Working Paper Number 167

\title{
Returns to Private and Public Education in Bangladesh and Pakistan: A Comparative Analysis
}

\author{
Mohammad Niaz Asadullah ${ }^{1 *}$
}

This paper documents wage differentials between private and public school graduates in Bangladesh and Pakistan. While evidence in support of a wage advantage of private school graduates in Bangladesh is lacking, Pakistani private school graduates are found to earn more than their public school counterparts. This finding has important implications for the current debate over the effectiveness of private schools in South Asia. To the extent the wage premium arises owing to education in private schools, our result suggests relative superiority of private schools in Pakistan and are consistent with extant studies that have assessed private school quality using testscores of students. The difference in the performance of private schools in the two countries, however, remains a puzzle. This difference, we conjecture, may be partly explained by the between-country differences in public policy towards private schools and, therefore, the regulatory regime facing these schools.

*Department of Economics, University of Reading Business School, UK.

May 2008

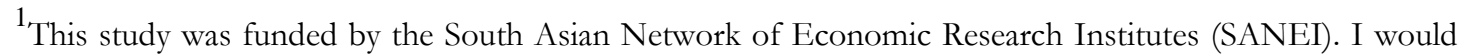
like to thank Geeta Kingdon, Emanuel Jimenez, Syed Pasha, Michelle Riboud and Francis Teal for their comments and suggestions. An earlier version of the paper was presented at the Education Research Initiative workshop organized by SANEI (New Delhi), research seminar at BRAC (Dhaka), Global Conference on Education Research in Developing Countries (Prague) and the UKFIET Conference on Education and Development (Oxford University). The usual disclaimers apply. Corresponding email: m.asadullah@reading.ac.uk
} 
In recent years, there has been considerable public pressure for the privatization of the education sector in developing countries. Proponents of privatization argue that in a privatized regime, teachers and school managers have better incentives and greater scope for innovation so that increased private sector participation would aid the process of skill formation in the economy. However, the impact of privatization is not adequately researched for developing countries. In one much publicised review of studies on Columbia, Dominican Republic, the Philippines, Tanzania and Thailand, Lockheed and Jimenez (1994) provide evidence supporting the effectiveness of secondary private schools over public schools, both in terms of student achievement and unit cost ${ }^{1}$. However, later studies on Tanzania (e.g. Lassibille and Tan, 2001) find that public schools are more effective than private schools in Tanzania in boosting student achievement. Not surprisingly, a review of the developing country literature points out that the relative efficiency of private and public schools has remained unresolved till date (Glewwe 2002). Indeed, the most recent developing country study on private school effectiveness, Uribe et al. (2006), draws upon student achievement data from Colombia and concludes that, on average, private and public schools are equally effective. A similar debate also continues in South Asia. The objective of this research is, therefore, to take the debate further by using comparable data on graduates of private and public schools from two South Asian countries, namely, Bangladesh and Pakistan ${ }^{2}$. We do so by estimating wage differentials between private and public school graduates -- a decomposition analysis of the wage gap across the two schooling sectors is carried out following Oaxaca (1973). Our analysis remains purely descriptive, however; we do not answer causal statements ${ }^{3}$. Rather, our intention is to provoke further research along these lines in South Asia.

For several reasons, we compare/contrast Bangladesh and Pakistan. First, only for these countries in South Asia are comparable wage data along with information on types of schools attended by individuals available. Second, Bangladesh and Pakistan have shared a common education policy during 1947-1971 and pursued similar policies even after separation in 1971. Apart from the above commonalities, an additional motivation for such a two-country comparison lies in the subtle difference in the structure of the private education sector in South Asia. A large number of private schools in Bangladesh at the secondary level are publicly aided. On the contrary, aided schools in Pakistan are nonexistent ${ }^{4}$. Hence, a joint study of Bangladesh and Pakistan provides an interesting setting where one could additionally assess the effectiveness of education sector de-regulation: the presence of a fully private education sector in Pakistan resembles a completely deregularized private regime in comparison to Bangladesh where dominance of aided schools symbolizes a partially de-regularized regime. Comparison of results for

\footnotetext{
1 Lassibille and Tan (2003) reached a similar conclusion using test score data on private and public (primary) school students in Madagascar.

2 An earlier study by Knight and Sabot (1987) makes a similar attempt using sets of comparable microeconomic data from two East African countries. The authors estimate returns to education in Kenya and Tanzania and also control for government school attendance in wage regression models. They report a positive premium for public school attendance in Kenya; no significant private-public wage gap is found for the Tanzanian data. However, their result is difficult to generalize as they investigate returns to private schooling only for a sample of urban wage employees.

${ }^{3}$ For a lack of valid exclusion restriction we have not addressed the problem of school selection. Although earlier studies on private school effect has used family background variables for identification purposes, this practice is now widely considered as inappropriate e.g. see Glewwe (2002) for a discussion.

${ }^{4}$ Only a few private schools in Pakistan occasionally receive one time grant from the government in the form of subsidized land etc. (Jimenez and Tan 1987).
} 
Bangladesh with that of Pakistan may help in understanding the factors that lead to variation in the performance of private and public schools within South Asia.

Our analysis reveals that students of private (aided and/or unaided) schools do not enjoy any wage advantage compared to those from public schools in Bangladesh. The opposite is true for Pakistan: individuals educated in private schools enjoy a wage premium over their publicly schooled peers. These findings point towards superior quality of private schools in Pakistan and are consistent with the existing test-score based evidence on the relative effectiveness of private schools in South Asia. We conclude by discussing a number of hypotheses to explain the relative superiority of private schools in Pakistan. The paper unfolds as follows. Section 2 provides a review of the literature on the relative effectiveness of private and public schools, with a focus on developing country studies. Section 3 provides an overview of the education sector in Bangladesh and Pakistan. Section 4 describes the data whilst section 5 elaborates on the methodology. Section 6 discusses the results for Bangladesh and Pakistan. Section 7 concludes.

A number of recent studies have studied private school quality in South Asia using primary data. Alderman et al. (2001) find evidence of higher mathematics and language achievements in private schools than in government schools in Pakistan. Khan and Kiefer (2007), Aslam (2007) and Das et al. (2006) use primary data on private school students in Pakistan and also conclude that students in private schools have higher test scores. Alderman et al. (2001) additionally show that even the poorest households use private schools extensively, and that utilisation increases with income. Once again, this observation is supported by recent research that use large-scale household and school survey data from rural Pakistan (e.g. see Andrabi et al., 2005).

The Indian literature is equally conclusive in favour of private schools. In a widely-cited study, Kindgon (1996) provides convincing evidence in favour of private schools using data from Northern India. Recent studies using nationally representative data on rural, private schools further corroborate Kindgon's earlier findings -- Muralidharan and Kremer (2008) find that even in rural India, private school children have relatively higher test scores.

Overall, recent research on private schools in India and Pakistan highlights two points. First, in terms of test-score, private schools are superior to public schools. Second, private schools cater to both urban and rural populations. The first finding has important implications for the process of economic development -- Alderman et al. (1996) find that for rural Pakistan, individuals with higher cognitive skills enjoy a substantial wage premium in the labour market. Therefore, low fee private schools can serve as an effective instrument for skill formation and poverty alleviation (via boosting wage earnings of individuals) in rural economies.

The findings of Alderman et al. (1996) together with the extant evidence of a positive private school effect in educational production function implies that one should expect a positive relationship between private school attendance and wage earnings. To be precise, an alternative approach to school effectiveness is based on labour market performance of individuals educated in different schools. This approach has been taken in Bedi and Garg (2000) who use Indonesian data ${ }^{5}$. Their wage decomposition analysis concludes that graduates of private secondary schools earn more than similarly endowed public school graduates in the labour market in Indonesia. The findings of Bedi and

\footnotetext{
${ }^{5}$ An additional innovation in the Bedi-Garg study is the attempt to correct the wage regressions for school selection effects.
} 
Garg, however, are somewhat inconclusive for two reasons ${ }^{6}$. First, (as also pointed out by the authors) the study does not address the possibility of non-random sorting into wage work. Second, it is not clear whether their analysis is robust to the exclusion of individuals employed in the public sector. This is because pay in the public sector sample may be a poor proxy for productivity.

Apart from Bedi and Garg, we are not aware of similar studies for other developing countries $^{7}$. There is no study on the issue using labour market data for Bangladesh ${ }^{8}$. For Pakistan, one study (i.e. Jamal et al. 2003) reports wage returns to private education using a Mincerian earnings function framework. Pakistani private school graduates are found to earn 16\%-18\% more than public school graduates, a finding that is consistent with extant test-score based research on private schools. It remains to be seen whether this is merely an artefact of data arising from incomplete decomposition of private-public schooling wage gap or if the result is truly suggestive of effectiveness of private education in Pakistan.

3 Brief overview of the private education system in Bangladesh and Pakistan Primary education in Pakistan and Bangladesh consists of a total of five years, followed by seven years of secondary education. In both countries, students appear in the Secondary School Certificate examination after completion of grade 10. For historical reasons, education sectors in the two countries are characterized by additional commonalities. Upon their separation from India in 1947, Pakistan and Bangladesh inherited an education system that largely constituted of private and local schools run by local government bodies (such as District Councils and Municipal Governments). By 1962, education, however, became fully provincialized so that respective governments were responsible for management and finance of schools (Asadullah, 2006b).

Immediately after the separation of Bangladesh and Pakistan, both countries undertook a policy of nationalisation of private schools. In 1972, all private schools in Pakistan were nationalised. By the early 1980s, however, both Bangladesh and Pakistan had recoursed to de-nationalization in the sense that an earlier moratorium on private sector participation in educational provision was withdrawn. Both countries opened up primary and secondary education sectors to private participation. In Bangladesh, this has also encouraged participation of NGOs in the provision of (non-formal) primary schooling, particularly in the 1990 s.

Whilst expansion of the non-formal sector has been limited in Pakistan, the mushrooming of formal private schools is today a well-known phenomenon. Private provision of education has increased tremendously, particularly in the 1980s, without explicit financial support from the government. The growth of private schools has increased the overall school enrolment. Enrollment in private primary schools is

\footnotetext{
${ }^{6}$ Indeed in a recent study using test scores on junior secondary school students, Beegle and Newhouse (2005) contradict Bedi and Garg (2000). They find no evidence that private schools are more effective than public schools at raising test score in Indonesia.

${ }^{7}$ However, there is a burgeoning literature on the issue for developed countries which show a "robust" correlation between higher earnings and private schooling (Brown and Belfield 2001). Brown and Belfield review four such studies for the US and eleven studies for the UK almost all of which use pooled wage regression with a dummy for private school attendance.

8 Test score based studies on private and public schools are also rare for Bangladesh. For instance, the only published study on secondary school quality is Asadullah, Chaudhury and Dar (2007). However, their dataset does not comprise of a representative sample of public schools. The only other study that exploits data on a large sample of public and private-aided schools is Asadullah (2005). Whilst this study does not formally evaluate the relative quality of public schools, it finds that controlling for various correlates of student examination performance, public schools are better than private-aided schools in Bangladesh.
} 
approximately $28 \%$ of the total enrollment $(14 \% \text { in } 1991)^{9}$. In the past, these schools were mostly an urban phenomenon. Today, $48 \%$ of them are located in the rural area (GoP 2001) and attract both girls and boys ${ }^{10}$. Nonetheless, these changes in enrolment patterns across school types are yet to be fully reflected in labour market outcomes. Given the relatively shorter history of private schools in Pakistan, private school graduates constitute a small fraction of the current labour force.

All private schools in Pakistan are mostly autonomous and free of government regulation in terms of ownership, management and finance (Andrabi, Das, and Khwaja, 2008). In contrast, a majority of private schools in Bangladesh are dependent on the government to finance teacher salaries. Such a public subsidy system has aided the growth of private schools in the country ${ }^{11}$. At the same time, through the provision of monthly aid towards teacher salary in private schools, government exercises a substantial amount of control over these schools, particularly in terms of teacher recruitment. A small fraction of private schools in Bangladesh do not take grants from the government and hence remains "unaided": they retain full autonomy over the management and finance of their schools (World Bank, 2000) ${ }^{12}$.

In sum, the structural differences in the finance and organization of the private education sector in these two countries are evident. A liberal, hands-off public policy towards private schools in Pakistan is in stark contrast to the Bangladeshi policy of financial and managerial regulation of private schools by the state. Such differences in regulation policy can create differences in incentives for school managers and therefore affect the input mix chosen by schools. Whether the liberal regime facing private schools in Pakistan creates better incentives and leads to efficient allocation of resources, nonetheless, remains an empirical question.

$4 \quad$ Data

Data used in this study comes from recent nationally representative household surveys that provide information on school type of adult householders along with their labour market earnings. For Bangladesh, the relevant household survey is the Household Income and Expenditure Survey (HIES) 1999-2000, conducted by the Bangladesh Bureau of Statistics. For Pakistan, we use the Pakistan Integrated Household Survey (PIHS) 2000-2001 dataset. Data from PIHS is comparable with that of HIES as both are designed after the World Bank's Living Standard Measurement Surveys. Sampling is based on a two-staged methodology where in the first stage, primary sampling units (PSU) are selected from all divisions/provinces. Households were randomly selected from each PSU in the second stage.

\subsection{Description of the HIES sample}

\footnotetext{
9 At the secondary level private schools account for $17 \%$ of enrollment ( $8 \%$ in 1991).

${ }^{10}$ For more discussion on this, see Kim et al. (1999). Partly motivated by these developments, the government of Pakistan is planning to provide additional incentives to the private sector to establish schools, particularly in rural areas and urban slums such as provision of free or subsidized land, noncommercial utilities rates, liberal grant of charters, and exemption of certain dues and taxes.

11 Approximately $93 \%$ of the secondary schools in Bangladesh are privately owned though aided by the government (World Bank, 2000).

${ }_{12}$ Minor differences also exist within the public education sector across Bangladesh and Pakistan. For example, a fraction of the existing public schools in Pakistan are actually run by Municipal corporations. These are local government bodies: schools under management of such bodies rely on the tax revenues earned by these local government bodies. While over a period of time, such schools have disappeared in Bangladesh, they have continued till date in Pakistan (Mingat and Tan 1987).
} 
The HIES 2000 provides data on a total of 7,440 households. We focus on a total of 22,433 individuals aged 19 years and above. From this sample, we further exclude individuals who work less than 50 hours a month. Also excluded are 3 "NGO school" educated individuals and 7 additional cases for whom school type is indeterminate as they are not in waged employment. Of the remaining 19,009 individuals 2447 waged workers, have non-zero years of schooling which become our working sample ${ }^{13} .47 .57 \%$ of the sample individuals are private aided school graduates $(\mathrm{N}=1164), 7.81 \%$ are private school graduates $(\mathrm{N}=191)$ and the rest are public school graduates $(\mathrm{N}=1050)^{14}$. Table 1

describes the characteristics of the working sample. Non-public school graduates appear to have a small ( $0.03 \mathrm{log}$ points) premium in wage over public school sample. More striking, however, is the significantly smaller mean years of schooling of public compared to non-public school sample.

Table 1: Summary statistics, HIES sample (Bangladesh)

\begin{tabular}{|c|c|c|c|c|c|c|c|c|c|}
\hline \multirow[b]{2}{*}{ Variable } & \multicolumn{3}{|c|}{ Pooled sample } & \multicolumn{3}{|c|}{ Public school } & \multicolumn{3}{|c|}{ Non-public school } \\
\hline & $\mathrm{N}$ & Mean & $\mathrm{SD}$ & $\mathrm{N}$ & Mean & $\mathrm{SD}$ & $\mathrm{N}$ & Mean & $\mathrm{SD}$ \\
\hline Hourly wage & 2447 & 2.46 & 0.71 & 1050 & 2.44 & 0.72 & 1397 & 2.47 & 0.70 \\
\hline Experience & 2447 & 22.14 & 11.68 & 1050 & 23.15 & 11.66 & 1397 & 21.39 & 11.63 \\
\hline Experience squared & 2447 & 6.27 & 6.34 & 1050 & 6.72 & 6.71 & 1397 & 5.93 & 6.02 \\
\hline Female* & 2447 & 0.10 & 0.29 & 1050 & 0.10 & 0.30 & 1397 & 0.09 & 0.29 \\
\hline Non Muslim* & 2447 & 0.12 & 0.32 & 1050 & 0.11 & 0.31 & 1397 & 0.12 & 0.33 \\
\hline Rural location* & 2447 & 0.41 & 0.49 & 1050 & 0.41 & 0.49 & 1397 & 0.40 & 0.49 \\
\hline Years of schooling (education) & 2447 & 8.26 & 3.02 & 1050 & 7.10 & 3.42 & 1397 & 9.13 & 2.34 \\
\hline Public school* & 2447 & 0.43 & 0.50 & -- & -- & -- & -- & -- & -- \\
\hline Private aided school* & 2447 & 0.48 & 0.50 & -- & -- & -- & 1397 & 0.83 & 0.37 \\
\hline Private (unaided) school* & 2447 & 0.08 & 0.27 & -- & -- & -- & 1397 & 0.14 & 0.34 \\
\hline Religious school* & 2447 & 0.02 & 0.13 & -- & -- & -- & 1397 & 0.03 & 0.17 \\
\hline
\end{tabular}

Note: * indicates dummy variable. Source: Author's calculations.

\section{Description of the PIHS sample}

The PIHS 2001 survey provides individual-level data on a total 16,182 households from all regions of Pakistan. Our working sample consists of 6898 individuals all of whom are aged 19 years or older and for whom data on wage and school information are nonmissing. We further exclude 138 cases for which school type is indeterminate ${ }^{15}$. For the resultant 6770 individuals, sample characteristics are reported in Table 2. An overwhelming 95.98\% of the sample individuals attended public schools in Pakistan. Of the remaining 272 cases, 233 attended purely private schools whilst for 15 individuals, the school was managed by private non-profit bodies (such as trust, foundation etc.). Similar to Bangladesh, there is also a small fraction $(0.36 \%)$ of waged workers who attended religious schools (or madrasas) in Pakistan ( $\mathrm{N}=24)$.

\footnotetext{
${ }^{13}$ The relatively small size of our working sample is explained by the fact that $56 \%$ of the sample adults (19 years and older) in HIES 2000 never went to school and approximately $70 \%$ of the population belong to the rural area where waged employment is limited.

14 There are 42 cases where reported school type is religious.

15 This also includes 8 individuals who received non-formal education.
} 
Table 2: Summary statistics, PIHS (Pakistan)

\begin{tabular}{|c|c|c|c|c|c|c|c|c|c|}
\hline \multirow[b]{2}{*}{ Variable } & \multicolumn{3}{|c|}{ Pooled sample } & \multicolumn{3}{|c|}{ Public school } & \multicolumn{3}{|c|}{ Non-public school } \\
\hline & $\mathrm{N}$ & Mean & SD & $\mathrm{N}$ & Mean & $\mathrm{SD}$ & $\mathrm{N}$ & Mean & $\mathrm{SD}$ \\
\hline Monthly wage & 6760 & 8.01 & 0.72 & 6488 & 8.00 & 0.71 & 272 & 8.39 & 0.89 \\
\hline Experience & 6760 & 18.60 & 11.65 & 6488 & 18.68 & 11.65 & 272 & 16.74 & 11.52 \\
\hline Experience squared & 6760 & 4.82 & 5.79 & 6488 & 4.84 & 5.81 & 272 & 4.12 & 5.28 \\
\hline Female* & 6760 & 0.09 & 0.29 & 6488 & 0.09 & 0.28 & 272 & 0.18 & 0.38 \\
\hline Rural location* & 6760 & 0.41 & 0.49 & 6488 & 0.43 & 0.49 & 272 & 0.13 & 0.34 \\
\hline Years of schooling (education) & 6760 & 9.28 & 4.11 & 6488 & 9.19 & 4.03 & 272 & 11.39 & 5.23 \\
\hline English Medium* & 6760 & 0.06 & 0.23 & 6488 & 0.04 & 0.20 & 272 & 0.34 & 0.47 \\
\hline Public school* & 6760 & 0.96 & 0.20 & -- & -- & -- & -- & -- & -- \\
\hline Private school* & 6760 & 0.03 & 0.18 & - & -- & -- & - & -- & -- \\
\hline Religious school* & 6760 & 0.00 & 0.06 & -- & -- & -- & -- & -- & -- \\
\hline Trust school* & 6760 & 0.00 & 0.05 & -- & -- & -- & -- & -- & -- \\
\hline
\end{tabular}

Note: * indicates dummy variable. Source: Author's calculations.

The PIHS 2001 does not have data on hours worked by individuals. We therefore use total monthly earnings from waged work as opposed to hourly earnings. Comparison of raw wage data by school types is indicative of a wage premium for private education in Pakistan. There are additional differences between private and public school graduates. Private school graduates are more concentrated in urban areas, have attained higher grades and are 9 times more likely to be educated in an English medium. Preliminary analysis of the enrolment data by school types further indicates that for current cohorts of school aged children (aged 5-19 years), 23\% are enrolled in private schools compared to only 3\% among adults (i.e. aged $20-60$ years). This is reflective of the fact that in Pakistan, most of the growth in private school enrolment is rather a recent phenomenon. However, our focus is only on adults who are observed in waged work. To be precise, we do not examine the effectiveness of private schools that have been set up in Pakistan in recent years (i.e. since the mid 1990s).

\section{$5 \quad$ Methodology}

In this paper, we fully decompose the private school wage premium following Oaxaca (1973). First, Mincerian earnings functions are estimated separately for private and public school graduates. Estimates of predicted earnings from these regressions are then used to decompose the wage gap. This approach decomposes wage gaps into two components: (i) a productivity component capturing differences in wages due to difference in productive endowment of individuals and (ii) a residual component capturing difference in the waged gap owing to differences in returns to individual characteristics ${ }^{16}$. If the residual component dominates the productivity component, say for private school graduates, it may be taken as a measure (albeit suggestive) of the effectiveness of private schools over public schools.

In the Oaxaca framework, mean differences in the explanatory variables in the private and public school graduate samples are weighted by the "non-discriminatory" wage structure to estimate wage differentials. There are a number of wage structures that are potential proxy for non-discriminatory wage structures (e.g. public school graduate wage structure, pooled wage structure etc.). We use pooled wage structure as weights in this

\footnotetext{
${ }^{16}$ The individual attributes are: experience, experience squared, whether the person is female, whether the work place is in a rural area and years of education. For Pakistan, we additionally control for the medium of education (in the last school attended) being English.
} 
study. Different weighting schemes may lead to different decomposition results. Therefore, we also test the robustness of our findings by repeating the analysis with alternative weights.

Apart from the index number problem, decomposing simple mean earnings gap could be problematic due to the presence of various selection problems effects. First, individuals may self-select into wage employment on the basis of some unobservables. Second, data on school types is only observed for individuals who have some schooling. Third, among the waged workers with some schooling, individuals may select endogenously into a given school type ${ }^{17}$. However, as pointed out earlier, our study is largely a descriptive one - solving problems of endogeneity and censoring is beyond the scope of the paper ${ }^{18}$. Lastly, a key limitation of the above approach is that it focuses on private school premium at the mean of the wage distribution. In the presence of heterogeneity in the sample of private and public school graduates, it may be of interest to examine earning differentials at different quantiles of the distribution for the following reason. Ordinary Least Squares (OLS) estimates of private school premiums on the conditional mean of earnings are not necessarily indicative of the size and sign of the effect at different tails of the wage distribution. Individuals at the bottom (top) of earnings distribution may be the ones with low (high) ability who attended poor quality private schools. Then decomposing the earnings gap at different points in the distribution may shed light on how school effectiveness evolves throughout the wage distribution for different (ability) groups in the labour market.

To test for disparity in the wage premium earned by private school graduates at different quantiles of the wage distribution, we also estimate series of pooled earnings-function with a dummy for private school attendance using the quantile regression method for each $\theta$ th quantile. Here, instead of conditional mean of earnings, we estimate $\theta$ th quantile of wages $(w)$ conditional on covariates. It is assumed that the conditional quantile of $w, \mathrm{q}_{\theta}$, is linear in $x$, i.e. $x=x \beta(\theta)$. The coefficient vector $\beta(\theta)$ is estimated as the solution to:

$$
\min _{\beta(\theta)}\left\langle\sum_{i: y_{i} \geq x_{i} \beta(\theta)} \theta\left|y_{i}-x_{i} \beta(\theta)\right|+\sum_{i: y_{i} \prec x_{i} \beta(\theta)}(1-\theta)\left|y_{i}-x_{i} \beta(\theta)\right|\right\rangle
$$

where, $\theta$ is bound between 0 and 1 (Koenker and Hallock, 2001). In this setting, the coefficient on the private school dummy is interpreted as the marginal effect of private school attendance on log wages at the $\theta$ th quantile of the log wage distribution. Results

Our decomposition analysis uses wage regression estimates for the pooled, private and public school graduates (see Appendix Table 1 for the estimated wage regression models). To this end, we first estimate regression models of log of hourly wage earnings with district fixed effects. Decomposition results are presented in Table 3, treating aidedand unaided-private schools graduates together as "private school" sample. From Table 3 , it is clear that there is a small, albeit statistically insignificant, "wage advantage" for private school graduates in Bangladesh in the raw data for the full sample. Examination of the decomposition results reveals that the wage premium for private school graduates is because of differential endowment of individuals. A substantial part of the wage gap however is due to the residual component (i.e. coefficient differences) which is negatively

\footnotetext{
${ }^{17}$ For instance, Kadrar (1995) reports a positive relationship between household income and enrolment of children in private schools in Pakistan.

18 Another related problem is selection into waged work. We discuss this issue later in the paper.
} 
signed, therefore, suggesting relative superiority of pubic schools in Bangladesh. Similar conclusions followed when we repeated the decomposition exercise using alternative weighting schemes. Furthermore, given that private-aided schools may have a different incentive structure from private unaided schools, we further carried out the decomposition analysis separating unaided private schools from aided ones. In all cases, our earlier conclusions remain unchanged ${ }^{19}$.

Table 3: Decomposing private-public wage gap (pooled wage structure as weights)

\begin{tabular}{lll|ll|ll}
\hline & \multicolumn{2}{l|l|l}{$\begin{array}{l}\text { Explained due to } \\
\text { characteristics difference }\end{array}$} & \multicolumn{2}{l}{$\begin{array}{l}\text { Unexplained differentials due to } \\
\text { coefficient differences }\end{array}$} & Total Wage gap \\
\cline { 2 - 7 } & Coefficient & $\begin{array}{l}\text { Standard } \\
\text { error }\end{array}$ & Coefficient & Standard error & Coefficient & $\begin{array}{l}\text { Standard } \\
\text { error }\end{array}$ \\
\cline { 2 - 7 } Bangladesh & .018 & -.151 & .020 & .023 & .027 \\
\hline Pakistan & .256 & .043 & .200 & .037 & .457 & .058 \\
\hline
\end{tabular}

Note: (a) Figures in parenthesis are percentages of total wage gap. (b) All the regressions for Pakistani sample include province fixed-effects. (c) t-test of difference in mean wage of private public school sample is significant at $1 \%$ level. Source: Author's calculations.

Turning to the Pakistani data, it is clear that most of the wage premium accruing to private school graduates is owing to differences in the productivity endowment of individuals in the labour market (see Appendix Table 2 for the underlying wage regression estimates). Having netted out the contribution of individual's characteristics, residual differentials in the wage gap owing to differences in the returns to these characteristics do not dominate as a percentage of total wage gap. This result remains unchanged as we apply different weighting schemes (i.e. different non-discriminatory wage structures) to our data and additionally control for occupation of sample individuals (results not reported). Hence, private school graduates in Pakistan earn more than their publicly schooled peers primarily because they possess superior individual characteristics. Nevertheless, the residual private school premium (net of individual characteristics) is also positive and substantial ( $43 \%$ of the total wage premium). This finding is consistent with the popular belief regarding the superiority of private schools in Pakistan. However, what specific aspect of private schools drives the higher return in Pakistan is not clear. Our regression analysis suggests that it is partly determined by higher returns to language skills (i.e. being educated in English etc.).

Our analysis of Bangladeshi and Pakistani data above has assumed that returns to education do not vary across levels of education. As pointed out earlier, in both countries, private school graduates have more years of schooling. If true returns to education are convex, we may undermine returns to private education in a linear specification. As pointed out in Asadullah (2006a), returns to education are convex in Bangladesh. Appendix Table 3 therefore reports estimates of returns to private schools obtained from regression models that additionally include a squared and cubic term of the schooling variable. Whilst the non-linear effects are significant, they are very similar for Bangladesh and Pakistan. It is reassuring that the inclusion of non-linear terms does not significantly affect the coefficient on the private school dummy for Pakistan. For Bangladesh, the coefficient on the aided school dummy is smaller but still significant and negative with the inclusion of the squared and cubic terms. Therefore our findings on the relative performance of private schools in Bangladesh and Pakistan cannot be explained by the convexity of returns to schooling.

\footnotetext{
${ }^{19}$ Results are available from the authors upon request.
} 
We further analyse the quantile regression estimates of coefficients on the private school dummy to the corresponding estimates from pooled OLS regressions to check whether looking at the average private school premium is adequate for our data. For the sake of brevity, we present quantile (and pooled OLS) regression estimates of the coefficient on the private school dummy in a graphical form. The graphs presented in this section are generated by retrieving the estimates of coefficients on the private school dummy from 19 quantile regressions and plotting these against the OLS estimate of the coefficient ${ }^{20}$. The bold unbroken curve connects the quantile estimates where the respective 95\% confidence interval is shown by the shaded area. The OLS estimate is identified by the bold, broken straight line. The $95 \%$ confidence interval for the OLS estimate is shown by a pair of dotted lines, parallel to each other.

Figure 1: OLS and Quantile regression estimates of private (i.e. non-government) school premium in Bangladesh $[\mathrm{N}=2447]$

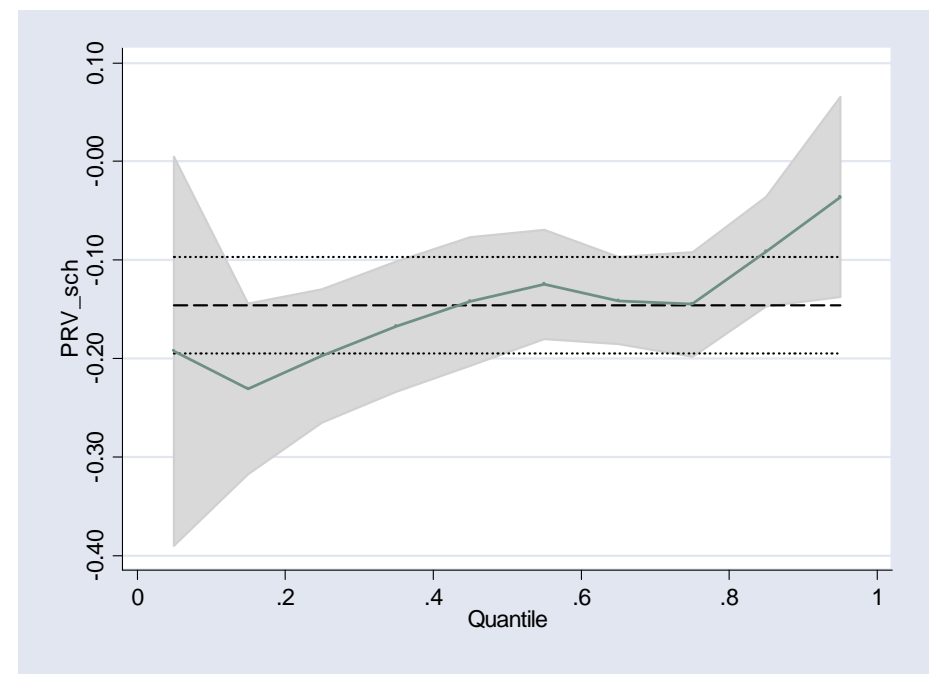

Note: The dependent variable is log of hourly wages. The wage premium refers to private schooling (defined by the variable "PRV_sch" which is $=1$ if a non-government school; 0 if a public school). Source: Author's calculations

Figure 1 plots the coefficient on the private school dummy where the base category is public school. All the underlying regressions additionally include a large number of district dummies and controls for experience (and its square), gender, religion and years of schooling completed ${ }^{21}$. The coefficient on the private school dummy is somewhat larger and negative at the bottom percentile although a much smaller negative at $95^{\text {th }}$ percentile. The extent of disparity in the quantile estimates is not large: the OLS confidence interval does a good job of presenting this range of disparity, at least up to the $85^{\text {th }}$ percentile. However, given the considerable heterogeneity within the private education sector in Bangladesh, we re-estimated the pooled regressions where we replace the private school dummy by a set of two dummies: (private) aided school and private (unaided) school $^{22}$.

\footnotetext{
${ }^{20}$ Therefore, $\theta$ in equation (1) ranges from 0.05 to 0.95 .

${ }^{21}$ District dummies control for cluster fixed-effects and hence partially reduce the scope for selection into private schools (given that between district migration is not significant). This is because some districts may have more private schools than others so that individuals residing there are more likely to attend private schools.

${ }^{22}$ We also control for attendance of religious private schools but discard these results as (a) we focus on secular private schools only and, (b) the corresponding sample is very small.
} 
Figure 2: OLS and Quantile regression estimates of private (i.e. non-government) school premium in Pakistan [N=6760]

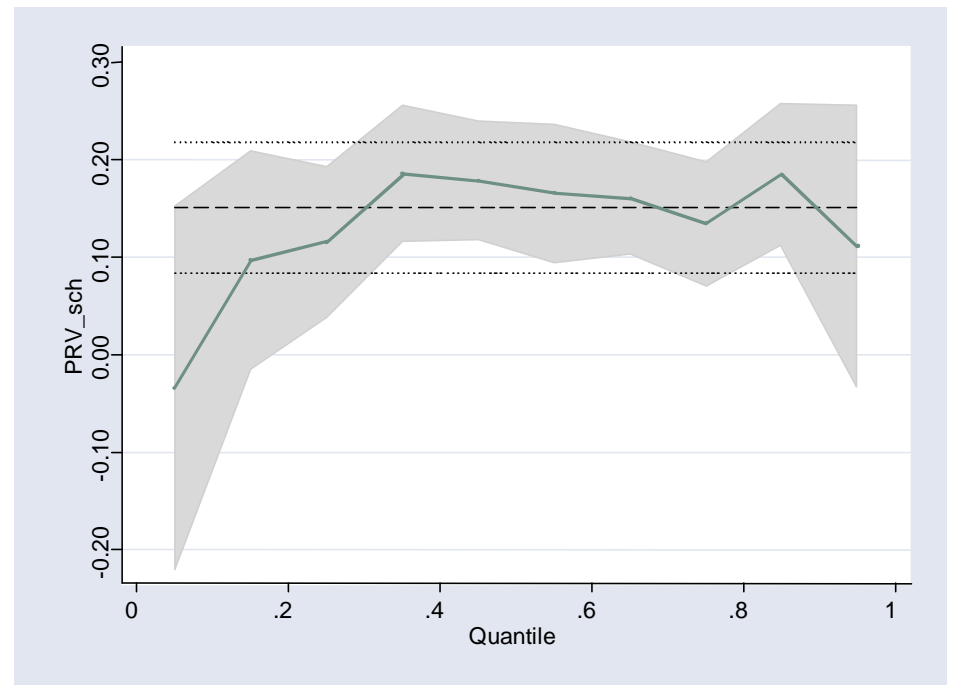

Note: The dependent variable is log of monthly wages. wage premium refers to private schooling (defined by the variable "PRV_sch" which is = 1 if a non-government school; 0 if a public school). Source: Author's calculations.

Similar analysis is repeated using Pakistani data. All the underlying regressions additionally include a set of province dummies and control for experience (and its square), gender, religion, years of schooling and a dummy for "medium of instruction is English". The graph of OLS and quantile estimates is suggestive of a private school premium for Pakistani data (Figure 2). The quantile estimates always lie within the OLS confidence interval and is very similar to the OLS point estimates at various points in the distribution.

Lastly, a problem not addressed so far in our analysis is selection of individuals into wage work. For Bangladesh, the HIES dataset contains information on household andholding and unearned income. We therefore use these data to construct the exclusion restrictions and estimate the Heckman regression model that corrects for selection into waged work $^{23}$. Overall, the evidence in support of selection effects into waged work was found to be weak ${ }^{24}$. Only in case of public school graduates was the lambda term significant. However, because of non-availability of data on non-earned income of the household, we could not test for selection effects in the Pakistani sample.

6 Conclusion and policy implications

This paper has looked at wage differences between private and public school graduates in Bangladesh and Pakistan within the context of the ongoing debate over the relative effectiveness of private schools in South Asia. Our decomposition analysis reveals that for private school graduates in Bangladesh, the earning premium is driven mostly by characteristics endowment of waged workers. Market return to these characteristics is rather negative and account for a smaller portion of the observed wage gap, which is suggestive of "ineffectiveness" of private schools vis-à-vis public schools. In contrast, decomposition of the mean wage gap for the Pakistani data shows that a substantial proportion of the private school premium remains even after netting out the

${ }^{23}$ Results are available from the authors upon request.

${ }^{24}$ This finding is consistent with other studies using the same dataset (e.g. Asadullah 2006a). 
contribution of differential attributes of the individual and is positive: graduates of private secondary schools earn more than similarly endowed public school graduates in the labour market in Pakistan. The reported evidence of wage premium by school type is nonetheless suggestive as potential for non-random selection into private schools remains, the solution to which is outside the purview of our descriptive analysis. However, to the extent to which school-specific selection bias is similar in Bangladesh and Pakistan, our result points towards greater effectiveness of private schools in the latter.

Altogether, our finding corroborates the existing research on the superiority of private schools in Pakistan that uses test score data ${ }^{25}$. Such consistency in the findings is particularly reassuring given that test score based studies capture the quality of newly established private schools (which may be structurally different from older private schools, mostly set up in the 1960s or earlier). At the same time, however, the betweencountry difference in the degree of effectiveness of private schools remains a puzzle. There are several potential explanations for this difference. The lack of relative advantage of private schools in Bangladesh could be attributed to the possibility that public schools in Bangladesh are subject to greater parental pressure than their counterparts in Pakistan. Consequently, the relative advantage of private schools, in terms of management autonomy is less in Bangladesh than in Pakistan. If public schools are controlled or influenced by the parents, they can be motivated to produce good results. Indeed this argument formed the basis for decentralization of public school management, in the form of introducing parent-teacher associations in schools in South Asia. However, such reform is a relatively new phenomenon in Bangladesh and hence not relevant as our study relates to pre-reform public schools only.

An alternative explanation could be found in the environment in which private schools operate in the two countries. Significant between-country differences exist in managerial autonomy over issues of teacher salary and recruitment. Private schools in Pakistan can recruit teachers at a low salary and are free to fire them if necessary. A vast majority of the rural private schools in Pakistan today mostly employ female teachers primarily because they are available at lower wages ${ }^{26}$. However, this is not the case in Bangladesh. Despite the absence of organized teacher unions, pay determination and teacher recruitment in the private sector remains rigid. This is because most of these schools operate in partnership with the government as aided schools. However, this does not explain why unaided private schools, as seen in Pakistan, did not burgeon in Bangladesh without support from the government.

Differences in labor market conditions could provide an explanation for the differential number and performance of competitive unaided private schools in the two countries. Between 1947-1971, the post-primary education sector in Pakistan expanded at a higher rate (partly at the cost of that in Bangladesh) so that by 1971, Pakistan had more schools at almost all levels and a greater number of higher educated individuals than Bangladesh

\footnotetext{
${ }^{25}$ Our conclusion for Bangladesh is also consistent with available test-score based evidence on the quality of private-aided and public schools (e.g. see Asadullah 2005).

26 Andrabi et al. (2005) provide a related explanation for the growth of private schools in Pakistan. The authors note that past expansion of female education in Pakistan has largely relied on public schools. This together with the prevalence of consangious marriages in the rural area has created a large pool of educated females in the local labor market when a public secondary school is present in the vicinity. Private schools in Pakistan have exploited the externality arising from public education and cultural labor market restrictions to their advantage. However, consangious marriages are less popular in Bangladesh so that educated women are more mobile when compared to their counterparts in Pakistan. This altogether limits the prospect for growth of low-cost private (unaided) schools based on past public investment in female secondary education in Bangladesh.
} 
(Asadullah, 2006b). In that sense, school supply in Bangladesh was historically more constrained compared to that in Pakistan. Consequently, private schools in Pakistan had access to a larger potential pool of cheap teachers compared to their counterparts in Bangladesh $^{27}$.

To conclude, the more plausible explanation for our finding -- private schools in Pakistan as opposed to those in Bangladesh, are more effective than public schools -- may be that private schools in the two countries differ significantly in terms of public policy towards private schools which subsequently shapes the regulatory environment and incentive regime. This is most likely to be true for private aided schools which have mushroomed over the past years in Bangladesh under guaranteed government finance, without any link between grant money and student achievement. Teachers and managers of aided schools today have little incentive to perform. As teachers of public and aided schools are paid on same salary scale, the same incentive problem plagues public schools so that aided and public schools have possibly become indistinguishable. The ineffectiveness and the shortage of private unaided schools in the country - free of government regulation nonetheless pose the biggest puzzle. Future research should investigate two issues. First, whether the effect of private school attendance on wages is causal. Second, whether the apparent lack of relative effectiveness of private unaided schools in Bangladesh is arising because the positive effect of private management is offset by superior physical infrastructure or/and student intake enjoyed by the latter.

\footnotetext{
27 This is somewhat similar to Knight and Sabot's account of secondary education in East Africa (1992). Kenya and Tanzania were similar in relevant respects except in their policies for secondary education and private schools. The former had a large (public and private) education system whilst the latter had a constrained supply of schools. The Tanzanian case therefore mirrors the Bangladeshi education system in the early years. In Tanzania, the government expressly limited the growth of secondary schools in order to equalize educational opportunities; in Bangladesh, this happened owing to historical reasons (Asadullah, 2006b).
} 
References

Alderman, Harold and Behrman, JR, Ross, DR and Sabot, R. 1996. "The returns to endogenous human capital in Pakistan's rural wage labour market" Oxford Bulletin of Economics and Statistics 58 (1): 29- \& Feb 1996.

Alderman, Harold, Peter Orazem, and Elizabeth M. Paterno. 2001. "School quality, school cost, and the public/private school choices of low-income households in Pakistan". Journal of Human Resources 36: 304-326.

Andrabi, T., Das, J. and Khwaja, A. I. 2005. "Students today, teachers tomorrow? The rise of affordable private schools", Unpublished manuscript, Harvard University.

Andrabi, T., Das, J. and Khwaja, A. I. 2008. "Private Schooling: Limits and Possibilities". Forthcoming, Comparative Education Review.

Asadullah, M. N. 2005. "The effect of class size on student achievement: evidence from Bangladesh," Applied Economics Letters, 12(4): 217-221.

14(4): 457-472. 2006a. "Returns to education in Bangladesh". Education Economics:

2006b. "Educational disparity in Pakistan, 1947-71: Was East

Pakistan discriminated against?" Oxford Economic History Discussion Paper no 63, Department of Economics, University of Oxford.

Asadullah, M. N., Chaudhury, N. and Dar, A., 2007. "Student achievement conditioned upon school selection: Religious and secular secondary school quality in Bangladesh," Economics of Education Review, 26(6): 648-659.

Aslam, Monazza 2007. "The quality of school provision in Pakistan: Are girls worse off?", GPRG working paper no 066, University of Oxford.

Bedi, Arjun and Ashish Garg. 2000. "The effectiveness of private versus public schools: the case of Indonesia". Journal of Development Economics 61(2): 463-494.

Beegle, C. and Newhouse, David. 2005. "The effect of school type on academic achievement: evidence from Indonesia". Policy Research Working Paper 3604, World Bank.

Brown, Celia and Clive Belfield. 2001. "The relationship between private schooling and earnings: a review of the evidence for the US and the UK". Teachers College Occasional Paper No 27, Columbia University.

Das, Jishnu, Pandey, P. and Zanoj, T. 2006. "Learning levels and gaps in Pakistan", World Bank Discussion Paper series no 4067.

Glewwe, Paul. 2002. "Schools and skills in developing countries: Education policies and socioeconomic outcomes". Journal of Economic Literature 40(2): 436-482.

GoP. 2001. Census of private educational institutions in Pakistan 1999-2000. Statistics division, Federal Bureau of Statistics (FBS), Government of Pakistan (GoP).

Jamal, Haroon, Imran Toor and Farhan Khan. 2003. "Private returns to education: evidence for Pakistan" Research Report no 5, Pakistan Institute of Development Economics.

Jimenez, E., M. and J. Peng Tan. 1987. "Decentralised and private education: the case of Pakistan". Comparative Education, 23(2): 173-90.

Kim, Jooseop, Harold Alderman and Peter Orazem. 1999. "Can private schools subsidies increase schooling for the poor?: The Quetta Urban Fellowship Program”. World Bank Economic Review 13: 443-466.

Kingdon, Geeta. 1996. "The quality and efficiency of public and private education: A case study of urban India". Oxford Bulletin of Economics and Statistics 58(1): 57-82.

Khan, R. and Kiefer, D., 2007. "Educational Production Functions for Rural Pakistan: A

Comparative Institutional Analysis". Education Economics, 15(3): 327-342.

Knight, J. and Sabot, R. 1992. Educational, Productivity and Inequality, The East African

Natural Experiment. Oxford: Oxford University Press. 
1987. "Educational Policy and Labor Productivity: An

Output Accounting Exercise”, Economic Journal, 97, pp. 199-214.

Koenker, Roger and Kevin F. Hallock. 2001. "Quantile Regression," Journal of Economic Perspectives 15(4): 143-156.

Lassibille, G and Jee-Peng Tan. 2003. "Student Learning in Public and Private Primary Schools in Madagascar". Economic Development and Cultural Change 51: 699-717.

2001. "Are private schools more efficient than public

schools? Evidence from Tanzania". Education Economics 9(2): 145-172.

Lockheed, Marlaine and Emmanuel Jimenez. 1994. "Public and private secondary

schools in developing countries: What are the differences and why do they persist?". ESP discussion paper series No 33, The World Bank.

Muralidharan, K. and Kremer, M. 2008. "Public and Private Schools in Rural India".

Forthcoming in School Choice International, ed. by Paul Peterson and Rajashri Chakrabarti. MIT Press.

Oaxaca, R. 1973. "Male-female wage differentials in urban labour market". International Economic Review 9: 693-709.

World Bank. 2000. Bangladesh Education Sector Review. Volumes I, II \& III. University Press Limited: Dhaka.

Uribe, Claudia, Richard Murnane, John Willett and Marie-Andree Somers. 2006.

"Expanding School Enrollment by Subsidizing Private Schools: Lessons from Bogotá".

Comparative Education Review, volume 50, pages 241-277. 
Appendix Table 1: Determinants of hourly wage earnings, HIES sample (Bangladesh)

\begin{tabular}{|c|c|c|c|}
\hline & Public school sample & Private school sample & Pooled sample \\
\hline \multirow[t]{2}{*}{ Experience } & 0.05 & 0.039 & 0.047 \\
\hline & $(9.60)^{* *}$ & $(8.22)^{* *}$ & $(13.45)^{* *}$ \\
\hline \multirow[t]{2}{*}{ Experience, squared } & -0.071 & -0.050 & -0.065 \\
\hline & $(7.92)^{* *}$ & $(5.39)^{* *}$ & $(10.19)^{* *}$ \\
\hline \multirow[t]{2}{*}{ Female } & -0.369 & -0.321 & -0.336 \\
\hline & $(6.73)^{* *}$ & $(5.86)^{* *}$ & $(8.61)^{* *}$ \\
\hline \multirow[t]{2}{*}{ Non-Muslim } & -0.075 & -0.200 & -0.133 \\
\hline & -1.33 & $(3.89)^{* *}$ & $(3.52)^{* *}$ \\
\hline \multirow[t]{2}{*}{ Rural work place } & -0.315 & -0.243 & -0.281 \\
\hline & $(8.20)^{* *}$ & $(6.59)^{* *}$ & $(10.61)^{* *}$ \\
\hline \multirow[t]{2}{*}{ Years of schooling } & 0.111 & 0.107 & 0.100 \\
\hline & $(21.01)^{* *}$ & $(15.35)^{* *}$ & $(25.40)^{* *}$ \\
\hline \multirow[t]{2}{*}{ Constant } & 1.154 & 1.095 & 1.166 \\
\hline & $(13.81)^{* *}$ & $(12.40)^{* *}$ & $(20.30)^{* *}$ \\
\hline $\mathrm{N}$ & 1050 & 1397 & 2447 \\
\hline Adjusted $\mathrm{R}^{2}$ & 0.39 & 0.22 & 0.30 \\
\hline
\end{tabular}

Note: Absolute value of $t$ statistics in parentheses. + significant at 10\%; ${ }^{*}$ significant at $5 \%$; ** significant at $1 \%$. All regressions are based on the OLS method and include control for regional fixed effects. Source: Author's calculations.

Appendix Table 2: Determinants of monthly wage earnings, PIHS sample (Pakistan)

\begin{tabular}{|c|c|c|c|}
\hline & Public school sample & Private school sample & Pooled sample \\
\hline \multirow[t]{2}{*}{ Experience } & 0.056 & 0.035 & 0.055 \\
\hline & $(29.43)^{* *}$ & $(3.01)^{* *}$ & $(29.59)^{* *}$ \\
\hline \multirow[t]{2}{*}{ Experience, squared } & -0.072 & -0.026 & -0.071 \\
\hline & $(19.16)^{* *}$ & $(1.02)$ & $(19.08)^{* *}$ \\
\hline \multirow[t]{2}{*}{ Female } & -0.612 & -0.548 & -0.594 \\
\hline & $(25.92)^{* *}$ & $(5.56)^{* *}$ & $(26.46)^{* *}$ \\
\hline \multirow[t]{2}{*}{ Rural work place } & -0.146 & -0.194 & -0.152 \\
\hline & $(10.73)^{* *}$ & $(1.56)$ & $(11.30)^{* *}$ \\
\hline \multirow[t]{2}{*}{ Years of schooling } & 0.094 & 0.109 & 0.093 \\
\hline & $(51.26)^{* *}$ & $(11.33)^{* *}$ & $(52.62)^{* *}$ \\
\hline \multirow[t]{2}{*}{ English Medium } & 0.315 & 0.309 & 0.397 \\
\hline & $(9.24)^{* *}$ & $(3.01)^{* *}$ & $(13.07)^{* *}$ \\
\hline \multirow[t]{2}{*}{ Constant } & 6.547 & 6.757 & 6.568 \\
\hline & $(222.78)^{* *}$ & $(42.22)^{* *}$ & $(229.46)^{* *}$ \\
\hline $\mathrm{N}$ & 6488 & 233 & 6721 \\
\hline Adjusted $\mathrm{R}^{2}$ & 0.44 & 0.52 & 0.44 \\
\hline
\end{tabular}


Appendix Table 3: Additional estimates of determinants of wage earnings in Pakistan and Bangladesh

\begin{tabular}{|c|c|c|c|c|}
\hline & \multicolumn{2}{|c|}{$\begin{array}{l}\text { Pakistan: Dependent variable is } \log \text { of } \\
\text { monthly wage }\end{array}$} & \multicolumn{2}{|c|}{$\begin{array}{l}\text { Bangladesh: Dependent variable is } \\
\text { log of hourly wage }\end{array}$} \\
\hline & $(1)$ & $(2)$ & $(1)$ & $(2)$ \\
\hline \multirow[t]{2}{*}{ Experience } & 0.055 & 0.055 & 0.045 & 0.044 \\
\hline & $(29.73)^{* *}$ & $(29.57)^{* *}$ & $(13.23)^{* *}$ & $(13.17)^{* *}$ \\
\hline \multirow[t]{2}{*}{ Experience, sq } & -0.071 & -0.071 & -0.062 & -0.061 \\
\hline & $(19.24)^{* *}$ & $(19.24)^{* *}$ & $(9.99)^{* *}$ & $(10.00)^{* *}$ \\
\hline \multirow[t]{2}{*}{ Female } & -0.599 & -0.617 & -0.349 & -0.350 \\
\hline & $(26.16)^{* *}$ & $(27.20)^{* *}$ & $(9.03)^{* *}$ & $(9.14)^{* *}$ \\
\hline \multirow[t]{2}{*}{ Non Muslim } & -0.148 & - & -0.130 & -0.132 \\
\hline & $(10.92)^{* *}$ & - & $(3.47)^{* *}$ & $(3.56)^{* *}$ \\
\hline \multirow[t]{2}{*}{ Rural workplace } & - & -0.146 & -0.263 & -0.269 \\
\hline & - & $(10.91)^{* *}$ & $(10.04)^{* *}$ & $(10.36)^{* *}$ \\
\hline \multicolumn{5}{|l|}{ Years of schooling } \\
\hline \multirow[t]{2}{*}{ Education } & 0.093 & -0.083 & 0.108 & -0.112 \\
\hline & $(52.26)^{* *}$ & $(5.71)^{* *}$ & $(26.09)^{* *}$ & $(1.81)+$ \\
\hline \multirow[t]{2}{*}{ Education, squared } & - & 0.017 & - & 0.017 \\
\hline & - & $(11.35)^{* *}$ & - & $(2.30)^{*}$ \\
\hline \multirow[t]{2}{*}{ Education, cube } & - & -0.000 & - & -0.000 \\
\hline & - & $(10.01)^{* *}$ & - & $(1.06)$ \\
\hline \multicolumn{5}{|l|}{ School type dummies } \\
\hline \multirow[t]{2}{*}{ Private school } & 0.222 & 0.217 & -0.189 & -0.123 \\
\hline & $(5.98)^{* *}$ & $(5.92)^{* *}$ & $(4.10)^{* *}$ & $(2.63)^{* *}$ \\
\hline \multirow[t]{2}{*}{ Religious school } & -0.425 & -0.384 & -0.392 & -0.359 \\
\hline & $(3.91)^{* *}$ & $(3.48)^{* *}$ & $(4.44)^{* *}$ & $(4.09)^{* *}$ \\
\hline \multirow[t]{2}{*}{ Private aided school } & - & - & -0.122 & -0.053 \\
\hline & - & - & $(4.74)^{* *}$ & $(1.92)+$ \\
\hline \multirow[t]{2}{*}{ NGO run school } & - & - & -0.517 & -0.463 \\
\hline & - & - & $(1.59)$ & $(1.43)$ \\
\hline \multirow[t]{2}{*}{ English medium } & 0.347 & 0.294 & - & - \\
\hline & $(11.07)^{* *}$ & $(9.08)^{* *}$ & - & - \\
\hline \multirow[t]{2}{*}{ Constant } & 6.788 & 7.042 & 1.195 & 1.895 \\
\hline & $(159.46)^{* *}$ & $(145.14)^{* *}$ & $(21.11)^{* *}$ & $(11.53)^{* *}$ \\
\hline $\mathrm{N}$ & 6760 & 6760 & 2447 & 2447 \\
\hline Adjusted $\mathrm{R}^{2}$ & 0.45 & 0.46 & 0.31 & 0.33 \\
\hline
\end{tabular}

Note: Absolute value of $\mathrm{t}$ statistics in parentheses. + significant at $10 \%$; ${ }^{*}$ significant at $5 \%$; ** significant at $1 \%$. All regressions are based on the OLS method and include control for regional fixed effects. Source: Author's calculations. 